\title{
O BRINCAR NA RELAÇÃO PARENTO-FILIAL: UM RECURSO DE INTEGRAÇÃO DA FILIAÇÃO ADOTIVA
}

\author{
Rebeca Nonato Machado \\ Pontifícia Universidade Católica do Rio de Janeiro \\ Renata Mello \\ Pontifícia Universidade Católica do Rio de Janeiro \\ Terezinha Féres-Carneiro \\ Pontifícia Universidade Católica do Rio de Janeiro
}

\begin{abstract}
Resumo
O trabalho discute o brincar como elemento significativo no processo de constituição da filiação adotiva, na perspectiva de pais e mães adotivos. Pensou-se a presença dos fenômenos transicionais, vividos nos jogos e nas brincadeiras entre pais e filhos, como recurso psíquico para a integração da identidade paradoxal da família adotiva. Este estudo faz parte de uma ampla pesquisa qualitativa sobre parentalidade e filiação adotivas, na qual realizamos entrevistas semiestruturadas, com 14 mães e 10 pais adotivos. Os dados obtidos foram analisados pelo método de análise de conteúdo de Bardin no modelo categorial. Observou-se que brincar foi valorizado pelos pais como indicador da boa qualidade relacional com os filhos. Os participantes expressam que, por meio das brincadeiras, eles e seus filhos compartilharam conteúdos internos, desenvolvendo uma intimidade e criando espaço para experimentarem juntos dilemas em torno do paradoxo da filiação adotiva e do enigma sobre as origens.
\end{abstract}

Palavras-chave: adoção; parentalidade; filiação; brincar; fenômenos transicionais.

\section{PLAY AND ADOPTIVE FILIATION: PROCESS OF INTEGRATION OF THE PARADOXICAL FAMILY IDENTITY}

\begin{abstract}
The work discuss playing as a significant element in the process of adoptive filiation constitution, from the perspective of foster parents. It was intended to think the presence of the transitional phenomena, lived in the games and in the playing moments involving parents and children, as a psychic resource for the integration of the paradoxical identity of the adoptive family. This study is part of an extensive qualitative research on parenting and adoptive filiation, in which we conducted semistructured interviews with 14 mothers and 10 adoptive parents. The data obtained were analyzed by the Bardin content analysis method in the categorical model. It was observed that playing was valued by parents as an indicator of good relational quality with their children. Participants express that through play they and their children shared internal content developing an intimacy, creating space to experiment together dilemmas around the paradox of adoptive filiation and the enigma about origins.
\end{abstract}

Keywords: adoption; parenting; affiliation; play; transitional phenomena. 


\title{
JUEGO Y FILIACIÓN ADOPTIVA. PROCESO DE INTEGRACIÓN DE LA IDENTIDAD FAMILIAR PARADOXAL
}

\begin{abstract}
Resumen
El trabajo discute el lugar del juego como elemento significativo en el proceso de constitución de la filiación adoptiva, desde la perspectiva de los padres y madres adoptivos. Fueron pensados los fenómenos transicionales, vivenciados en el juego entre padres e hijos, como recurso psíquico en la integración de la identidad paradoxal de la familia adoptiva. Este estudio es parte de una amplia investigación cualitativa sobre parentalidad y filiación adoptiva, en la cual fueron realizadas entrevistas semiestructuradas con 14 madres y 10 padres. Los resultados obtenidos fueron analizados según el método de análisis de contenido de Bardin, en el modelo categorial. Fue observado que el jugar fue valorado por los padres como indicador de buena calidad relacional con los hijos. Los participantes expresan que, a través del juego, ellos y sus hijos compartieron contenidos internos desarrollando intimidad y creando espacio para experimentar juntos algunos dilemas en torno del paradojo de la filiación adoptiva y el enigma sobre el origen.
\end{abstract}

Palabras clave: adopción; parentalidad; filiación; jugar; fenómenos transicionales.

\section{INTRODUÇÃO}

Os vínculos de filiação e parentalidade adotivas ocorrem fundamentalmente porque houve a escolha dos adotantes e a descontinuidade dos laços da criança com a família de origem. Estas especificidades que instituem a família adotiva trazem à tona questionamentos profundos, inerentes à formação da relação de parentesco: "O que, ou quem, determina o meu pertencimento nessa família"? "Para vocês, quem sou eu"? "Por que me escolheram"?

Ciccone, Gauthier, Golse e Stern (2016) afirmam que em cada século as práticas e eventos histórico-culturais ativam angústias existenciais específicas na sociedade. Portanto, de maneira geral, todo sujeito imerso na cultura acaba sendo atravessado, de algum modo, por determinados conflitos. Para os autores, nos tempos atuais, vigoram de maneira pungente os questionamentos sobre as origens nos mais variados contextos de possibilidade da filiação (barrigas de aluguel, tratamentos de fertilização, produções independentes, famílias homoafetivas, dentre outras possibilidades de gerar ou de ter um filho). A partir das novas configurações familiares uma nova cultura de composição de parentesco é criada, contestando a normatividade de um filho ser gerado pela relação sexual conjugal entre um homem e uma mulher. Roudinesco (2003) demarca que o debate sobre as origens na sociedade se iniciou com a incapacidade de pais homoafetivos negarem as condições biológicas da filiação.

Portanto, a inquietude em relação ao enigma da origem não se restringe ao campo da adoção, apesar de neste contexto as indagações acerca do pertencimento familiar e do nascimento serem complexas. Machado, FéresCarneiro, Magalhães e Mello (2019) argumentam que Freud (1913/2006, 1914/2006, 1924/2006) já mencionava os questionamentos acerca da origem como conteúdos mobilizadores da constituição dos sujeitos de modo geral, fazendo parte do desenvolvimento psíquico e da constituição da subjetividade. 
Na psicanálise, as fantasias originárias e os mitos de origem possuem um caráter de busca de solução para o grande enigma da existência humana 'quem eu sou?' e 'de onde eu vim?'. Cada sujeito acaba desenvolvendo uma teoria sobre sua própria história de vida e criando uma narrativa predominante, a qual tem como núcleo a fantasia da cena primária - o coito dos pais. Abrão (2014) afirma que a necessidade humana de decifrar a si mesmo e seu nascimento é inerente a todo sujeito, sendo vivida de maneira mais aguçada no contexto da adoção, já que a cena primária não está vinculada ao casal parental adotivo.

Freud (1905/2006) observou que a natural curiosidade infantil sobre o nascimento dos bebês era fomentada pela angústia de encontrar uma verdade explicativa da própria existência, além de atender ao desejo de garantir um lugar no desejo dos pais (Santos \& Lajonquière, 2010). Entendemos que todo processo de filiação é permeado por esses conteúdos psíquicos, sendo organizado por uma trama complexa de desejos e representações conscientes e inconscientes.

Pierron (2003) enfatiza que normalmente os questionamentos ligados às origens acabam recebendo da sociedade ou das famílias respostas curtas e simplistas, não abarcando a verdadeira complexidade do processo identitário geracional. $O$ autor pontua que a condição de parentesco na adoção coloca em xeque qualquer definição reducionista sobre os vínculos familiares, desvelando elementos que, muitas vezes, permanecem invisíveis na relação parento-filial.

No espaço das relações de parentesco se consolidam os primeiros vínculos afetivos e jurídico-sociais, propiciando ao sujeito desenvolver a filiação, o senso de pertencimento e representação de si mesmo. Por filiação, entendemos um processo familiar universal, o qual envolve as dimensões biológica, jurídico-social e subjetiva (Queiroz, 2017). A sociedade, por muito tempo, ancorou a legitimação da filiação unicamente no eixo da biologia, mesmo que a prática da adoção estivesse presente desde os primórdios da humanidade.

Entretanto, o advir das condições de ser filho e da parentalidade não se sustentam pelas leis da natureza, mas sim por meio do jogo intersubjetivo que designa cada pessoa envolvida a criar um lugar específico na cadeia simbólica geracional (Pierron, 2003). A concepção de parentesco pela adoção se apoia no entendimento de que a formação da identidade familiar é constituída por uma narrativa relacional-afetiva e social, criada em um jogo de reconhecimento mútuo e de acolhimento à alteridade de cada integrante do grupo.

Encontramos destaque na literatura para a importância de a família conversar sobre as origens da adoção (Peiter, 2011; Rotenberg, 2011; Silva, 2011; Souza \& Casanova, 2011). Constata-se que, para o filho adotivo construir sua identidade, é preciso que o sistema familiar legitime seu lugar na cadeia geracional. Esse processo será possível pela construção de uma narratividade sobre a história de vida, a qual vira uma 'verdade histórica familiar', criada na contínua vivência de experiências emocionais familiares compartilhadas. 
$\mathrm{Na}$ convivência entre os membros familiares estão presentes fantasias referentes à legitimidade da filiação e da parentalidade adotivas. Levinzon (2000) destaca a fantasia do mau sangue, na qual os pais relacionam à família de origem as transmissões de características negativas para a criança. Outra comum, de acordo com a autora, é a fantasia de roubo, constituída pela condensação entre o desejo de ter um filho e um desejo irracional de retirar uma criança de seus pais biológicos para realizar a demanda da parentalidade. Kernberg (1985) aprofunda a reflexão sobre essa experiência emocional, afirmando que ela também é alimentada pelas naturais fantasias infantis de roubo de bebês de mãe, ou seja, de introjeção impiedosa dos conteúdos internos maternos férteis.

Compreendemos que a intensidade das fantasias que salientamos será acentuada pelo tipo de representação de parentesco em que o indivíduo ou a sociedade se apoiam. Se o fundamento da identidade familiar estiver na valorização do eixo biológico/genético, possivelmente a adoção acaba sendo concebida como uma vinculação secundária, faltosa e pouco sólida. Quando a família se organiza sob o modelo de que toda filiação se estrutura pelo ato de se adotar (de envolver-se e doar-se para um ser dependente $e$ em desenvolvimento), maior será a capacidade de consolidar a adoção em uma concepção de 'filiação incondicional'. Nesses casos, o grupo familiar constitui seus laços alicerçados na convicção de que toda criança para se tornar filho precisa, sobretudo, ser 'abraçada' como tal (Levinzon, 2009; Motta, 2018).

Sob o mesmo ponto de vista, Levinzon (2009) afirma que o grande desafio de uma família adotiva se localiza no tipo de fantasia em relação à filiação. De acordo com a autora, a qualidade da filiação organiza o senso de pertencimento e, para isso, vários fatores estão envolvidos. Como complementação a essas formulações, devemos ficar atentos para os significativos efeitos da mutualidade nos processos de filiação e de parentalidade, destacando que se desenvolvem necessariamente no acontecimento de um encontro entre pessoas (Herlem, 2013).

Devido à potência da presença, convoca-se e se é convocado a participar de uma relação específica. É na "presentificação" dos sujeitos que o inesperado do encontro se impõe, pois a materialidade do outro instaura repercussões que podem ser criativas ou destrutivas para a manutenção dos vínculos (Puget, 2015). Dessa maneira, a filiação e a parentalidade vão se moldando e sendo geradas no campo do contato humano e não exclusivamente no da biologia.

A criança adotada participa de um diferente jogo simbólico com os pais adotantes, carregando as inscrições da família progenitora. Para os pais adotivos concerne a tarefa de identificar e dar significado às demandas dos filhos relacionadas às suas origens. Devido à necessidade de os pais realizarem uma fina escuta das experiências emocionais de seus filhos, a adoção acaba sendo socialmente apontada como uma parentalidade vulnerável, já que muitas vezes 
os pais têm seus ouvidos obstruídos por fantasias conflituosas, algumas delas já mencionadas, e por feridas narcísicas.

Na parentalidade adotiva é acrescentada aos pais a função de costurar os diferentes registros/narrativas, auxiliando a criança no processo de integração de sua história de vida e de suas fantasias em decorrência da mesma. O filho adotivo precisará de alguma forma compreender que sua família de origem pôde Ihe dar a vida e à família adotiva coube ajudá-lo a crescer e enraizar-se. Histórias precisarão ser suturadas, a partir de um encontro entre vários sujeitos, narrativas e vivências emocionais. Nesta trajetória, é importante indagarmo-nos quais processos e recursos psíquicos pertencentes aos núcleos de saúde emocional ajudam nessa empreitada da formação da filiação.

Consideramos que determinados elementos se constituem como paradigma da filiação adotiva. Dentre eles, estariam as fantasias, a capacidade de a família elaborar as vivências com relação à alteridade e ao paradoxo da dupla filiação (Herlem, 2013; Ladvocat, 2018), bem como oferecer um espaço de escuta às agonias e demandas latentes do filho adotivo, e ter disponibilidade emocional para criar a intimidade familiar-afetiva.

A condição de dupla filiação na adoção corresponde ao paradoxo de a identidade adotiva envolver o sentido de "pertencer e não pertencer" concomitantemente. Juridicamente se é pai/mãe e filho incontestavelmente, porém na origem da existência os membros da família não estavam interligados, não pertenciam uns aos outros. A experiência desse paradoxo torna a condição adotiva mais trabalhosa psiquicamente (Konicheckis, 2001). Os pais possuem a tarefa de desfazer confusões internas, por vezes, inevitáveis, que ocorreram antes do convívio familiar.

Neste trabalho, a partir do relato da experiência de pais e mães adotivos, propomos pensar o brincar, na convivência familiar, como uma atividade parento-filial que auxilia na integração dessa condição paradoxal adotiva. A experiência do brincar permite às crianças pequenas a vivência do mundo interno na área externa. A brincadeira pertence a uma área intermediária, entre o princípio de prazer e o princípio de realidade, conciliando ilusão e fato. Assim, forma-se a terceira área, a qual foi concebida por Winnicott (1975) como um espaço entre o mundo interno e o externo. Não se trata apenas de uma fronteira entre o interno e o externo, mas de um espaço específico e primordial, "reino das passagens, das travessias, das jornadas" (Gurfinkel, 2017, p. 383).

Portanto, nessa área intermediária, seria possível ter a experiência emocional da presença paradoxal tanto de conteúdos subjetivamente concebidos quanto dos objetivamente percebidos, sem a preocupação de separar os dois mundos (interno e externo). Devido a essa característica, acaba sendo um espaço de descanso e relaxamento, onde o paradoxo não é sinal de confusão e sim de possibilidades, de inovação. 
Não se trata da área do discurso, mas da experiência da imaginação junto com o princípio de realidade (Rochel, 2018). Desse modo, o fenômeno transicional permite o compartilhar da experiência ilusória, repousando a necessidade do teste de realidade. Segundo Winnicott (1975), essa seria a base na formação dos grupos para uma similaridade de experiências. Ele concebe esses fenômenos, que dão origem ao brincar, como meios de lidar com o gradual e o estruturante fracasso do ambiente suficientemente bom. O brincar oferece, portanto, um espaço onde é possível recordar, reviver, sonhar e integrar a temporalidade do passado, presente e futuro (Safra, 2006).

Pensando nessas funções dos fenômenos transicionais no contexto da adoção que este trabalho foi proposto, tendo como objetivo discutir o brincar como elemento significativo no processo de constituição da filiação adotiva. Buscou-se pensar a presença dos fenômenos transicionais, vividos nos jogos e nas brincadeiras entre pais e filhos, como recurso psíquico para a integração do paradoxo da identidade familiar adotiva.

\section{MÉTODO}

Este trabalho faz parte de uma ampla investigação sobre a constituição da parentalidade adotiva, na qual realizamos 24 entrevistas com roteiro semiestruturado, com sujeitos independentes (pertencentes a diferentes famílias), dentre eles 14 mães adotivas e dez pais adotivos. Não foram realizadas entrevistas com os filhos adotivos, posto que a finalidade era focar na experiência parental adotiva. O roteiro implícito de perguntas foi criado a partir da revisão da literatura, constando temas relacionados à construção da parentalidade e da filiação, bem como questões relativas à adoção.

O acesso aos participantes ocorreu por meio de indicações originadas da rede social da equipe de pesquisa, configurando uma amostra de conveniência. Os participantes pertenciam a diferentes configurações familiares, tendo realizado adoções precoces e/ou tardias. Desse modo, a idade dos filhos à época da adoção variou entre 15 dias de vida a 14 anos.

As entrevistas tiveram duração entre trinta minutos e duas horas, sendo o local, a data e o horário agendados de acordo com a disponibilidade dos participantes. As mesmas foram gravadas em áudio e, posteriormente, transcritas integralmente. Como método, utilizamos a análise de conteúdo (Bardin, 2011), seguindo o ciclo de compilação dos dados, depois decompondoos para a criação das categorias desveladas a partir das narrativas, estruturando assim a análise categorial dos dados. No relato dos entrevistados foi possível identificar a descrição de experiências de brincar com os filhos, durante a rotina familiar, como um elemento valorizado para o reconhecimento da qualidade relacional. Esse dado foi significativo e compôs uma categoria de análise, cujo desdobramento e discussão compõem os objetivos deste artigo. 
A pesquisa obteve aprovação de Comitê de Ética do Instituto de Neurologia Deolindo Couto - INDC/UFRJ (Processo: 1.064.13), por meio da Plataforma Brasil. Todos os participantes assinaram o Termo de Consentimento Livre e Esclarecido, autorizando a divulgação dos resultados para ensino, pesquisa e publicação. A fim de ser mantido o sigilo, os nomes foram substituídos e detalhes da história familiar ocultados. Foi necessário fazer determinadas alterações, sem comprometer as análises, para que se mantivesse o compromisso ético da preservação da identidade dos entrevistados e membros familiares. Para a apresentação dos resultados, as mães foram nomeadas de um a 14 (M1 a M14) e os pais de um a dez (P1 a P10).

\section{RESULTADOS E DISCUSSÃo}

Nas famílias adotivas, os laços são atravessados pela lembrança de que um dia não se pertenceu originalmente à cadeia familiar de um e de outro. Em um momento inicial, pais e filhos estavam desconectados em suas vidas. Este fato desencadeia um esforço para transformar as ausências em presenças. Um exemplo disso é a reflexão da Mãe 5 na busca de elaborar o fato de não ter vivido os momentos iniciais com seu filho adotivo. Ela mencionou sua preocupação a um amigo: "Cara, vai ter sempre faltado um pedaço. Sempre perdeu um pedaço da história da criança, né? Na adoção, não tem como você não perder um pedaço." Esta participante revela como se sentiu acolhida quando esse amigo pôde legitimar sua dor, mas também fazê-la pensar que:

É isso mesmo, vai perder um pedaço. É ruim. E, eu acho que me senti melhor [risos] com isto, do tipo: 'é tudo bem, é uma coisa que todo mundo fica chateado, mas, ok, né'!? Tudo bem, por que a gente vai conseguir conviver com isso. Vão ter tantas ... isso foi outra coisa que eu vi: 'cara, tudo vai ser a primeira vez'. Tudo! Mesmo que a criança já ande, tudo vai ser a primeira vez, porque vai ser a primeira vez pra você e vai tá chegando numa família. (Mãe 5)

A reflexão dessa mãe é importante, já que ressalta a necessidade de se "com-viver" com as faltas/tristezas/frustrações, e acima de tudo com o paradoxo de que não se foi fonte do nascimento, porém se é fonte para o nascimento de uma família adotiva. Os momentos novos de convivência são originários desse conviver que inaugura o parentesco. A compreensão dessa mãe corrobora a afirmação de Davis e Wallbridge (1982) de que o grupo familiar forma sua identidade a partir das experiências que compartilhadas pelos seus membros.

Como mencionamos, a formação da parentalidade e da filiação envolve vivências emocionais complexas, as quais, para serem de fato solidificadas, precisam ser vividas na mutualidade. Conforme destacamos anteriormente, a presença dos sujeitos traz ao encontro algo inédito à experiência dos vínculos (Puget, 2015). Esta experiência de mutualidade organiza o senso de intimidade, dando espaço a um cuidar parental que vai além do compromisso de manter a 
sobrevivência de seu filho, ou de sua responsabilidade biológica. Trata-se na verdade de permitir um genuíno estar com, abrindo espaço para sensações afetivas significativas e compartilhadas que fortalecem o desenvolvimento do vínculo familiar (Davis \& Wallbridge, 1982).

Tanto as crianças como os pais precisam da "presentificação" mútua para o desenvolvimento da relação parento-filial, permitindo a construção da solidez do vínculo. Isto não é algo que se constitua pela via da racionalização, nem mesmo mecanicamente vivido. Trata-se de um trabalho que viabiliza a formação da intimidade familiar.

Observamos que muitos pais e mães, apesar de não exemplificarem ou darem ênfase aos detalhes, descreveram a presença da prática de brincar e jogar com os filhos como indicadores de boa qualidade relacional parento-filial e de solidez da intimidade. Por vezes, espontaneamente ilustravam o companheirismo e a comunicação íntima entre eles, narrando as brincadeiras.

Brincam muito, de futebol. Ele chega do trabalho cansado, com fome só bota a pasta dele lá. Tira o sapato e vai jogar bola com ela no quintal. Aí joga bastante bola com ela. Solta pipa com ela. Deixa tudo o que tem que fazer. Às vezes deixa trabalho, e vai fazer meia noite, mas não deixa de fazer as vontades dela, de brincar com ela, de sair com ela. (Mãe 6)

Então, existe esse limite que eu sempre coloquei, né? Mas eu procuro brincar, eu procuro. $E$, às vezes, a gente tira da onde a gente não recebeu né, o que a gente não tem. O meu pai trabalhava muito e passava pouco tempo dentro de casa e tal. Mas é... lembranças do meu pai brincando com a gente são pontuais, muito pouca coisa. A gente tenta passar um pouco do que a gente não recebeu pra eles [filhos], na certeza de que essa relação entre brincar e impor limites no meio. Ele [filho adotivo] tem que aprender que ele tem um pai amigo, mas que precisa respeitá-lo, né? Que não é o amiguinho da escola. É o pai que tá falando, é diferente, né? (Pai 8)

A gente teve alguns problemas no caminho que foram superados, graças a Deus, e a gente teve muita ajuda também. [A escola recomendou frequentarem um espaço de prevenção pra questões emocionais]. E aí eu levei a [filha] e amei, porque eles tinham umas sessões da mãe com o bebê que eram maravilhosas, com bolha de sabão era, assim, super prazeroso e a gente aprendia muitas brincadeiras também, né? Que o bebê gostava, muito bacana. (Mãe 4)

Como podemos ver nos trechos destacados, pais e mães frisaram que as experiências de brincadeira, jogar, espontaneidade e humor são momentos marcantes, permanecendo como registros significativos da boa convivência parento-filial. Lebovici e Diatkine (1988) afirmam que o jogo é uma forma de expressão do desejo de buscar o outro, a quem a criança procura imitar, contrariar, internalizar regras da cultura e da própria condição de estabelecer relações. Desse modo, entendemos que os pais revelam o quanto a área intermediária os auxilia na construção e manutenção da intimidade, portanto, a se sentirem próximos e vinculados aos filhos. No momento em que essas 
experiências emocionais são estabelecidas, os processos de filiação e parentalidade são construídos por esses registros.

Podemos pensar que a brincadeira ocupa um valor importante para os pais, por ser uma experiência compartilhada (Winnicott, 1975), que nem pertence à realidade psíquica, nem tampouco é originada da realidade externa. 0 Pai 4 destacou que as lembranças mais significativas da infância do filho adotivo foram as brincadeiras, os instantes de bom humor vividos conjuntamente. O Pai 6 afirmou que se percebia participante na vida da filha e isto o fazia se sentir fortalecendo sua relação com a mesma, concebendo o brincar como uma forma de consolidar a identidade, de "ser presente" como pai. Estes dois pais, bem como a Mãe 6, associaram claramente a importância dessas experiências de brincar ao desenvolvimento do senso de pertencimento familiar.

Ah, ele sempre foi muito risonho, brincalhão, não parava quieto. Essas coisas a gente tem dele. De ele estar sempre falando, falando com todo mundo. É essa coisa da infância que marca - a alegria, o sorriso dele. Que como eu disse, eu não me sinto pai adotivo, mas você... É se doar para aquilo ali... É tentar dar o seu melhor, porque a gente nunca consegue, né, assim, na vida. Mas fazer o melhor que você pode pro filho e buscar aqueles pequenos momentos felizes juntos, sabe. Poder sentar com ele, rir, brincar, mexer um com o outro. (Pai 4)

Eu acho que é a presença, né? Você se fazer presente. Porque no caso dela, assim, ela teve criação por parte da mãe e dos irmãos mais velhos [família de origem], mas não teve pai. Ela tem um pai [biológico], mas que nunca foi presente. Então, assim, é se fazer presente. Você estar do lado olhando as dificuldades, os acertos, você elogiar também... E antes de dormir ela vem, dá um beijo de boa noite, dá um beijo na mãe. Aí eu vou lá, às vezes ela quer brincar antes de dormir, aí eu tenho que pegar no colo, botar na cama, cobrir. (Pai 6)

Os trechos destacados ilustram que a parentalidade envolve muito mais do que a função de gerar, alimentar, educar. Trata-se de oferecer condições dignas e favoráveis para o desenvolvimento humano e do self da criança, sendo uma delas o brincar, por meio do qual se estabelece o ouvir, o dedicar-se ao outro, o contato emocional, o diálogo, o fantasiar compartilhado. No espaço transicional, fatos e ilusões se misturam permitindo que conteúdos internos possam ser conjuntamente experimentados. É nessa vivência intersubjetiva que se tem a chance de criar algo novo e de pensar diferentes soluções.

Motta (2018) menciona que o jogar possibilita um preparo para a vida, dando espaço para a simbolização, a integração e o desenvolvimento da tolerância aos conflitos, capacidades estas que promovem a saúde mental, conciliando internamente as vivências paradoxais e ambivalentes. Os participantes, ao mencionarem espontaneamente o brincar, revelam inconscientemente a importância desse processo na relação parento-filial. 
Safra (2006) ressalta que a criança quando cria um jogo, a partir dos objetos que lhe foram oferecidos, faz com que sua biografia seja atuada. Portanto, por meio da brincadeira, é possível fazer leituras do passado, de angústias relacionadas à história e vislumbrar saídas para o futuro. Essa seria justamente uma das singularidades mais significativas à prática do brincar, à viabilização de uma atividade transformadora das realidades psíquica e externa (Paes \& Zornig, 2018). O brincar e a experiência cultural "vinculam o passado, o presente e o futuro", ocupando tempo e espaço (Winnicott, 1975, p. 151). Sendo assim, une dimensões para a criação de algo novo, para a viabilização da experiência conjunta, possivelmente solidificando o processo de filiação e de parentalidade.

Para Fulgencio (2016), a ação do brincar é, em si mesma, terapêutica, não propriamente pelos elementos simbólicos que ela veicula, mas pelo fato de que é no brincar que a criança expressa a si mesma, a sua liberdade de criação, e por meio da qual ocorre a comunicação íntima e profunda entre os seres humanos. Dentre os conteúdos mais profundos no contexto da adoção, que demanda uma comunicação íntima familiar, está o enigma sobre as origens (ocupando um lugar variado pelos diferentes membros familiares). Para a criança, a realidade da separação em relação à família original e a conciliação entre experiências de ausência e presença, fazem parte da experiência familiar adotiva. Uma ilustração disto foram os relatos de alguns pais e mães comentando que seus filhos, mesmo sabendo sobre a história de origem, em algum momento pediram ou verbalizaram o desejo de "sair da barriga" da mãe adotiva. Percebemos o quanto os pais se surpreenderam com tal pedido.

O [filho adotivo] está sempre fazendo carinho na nossa barriga. Perguntou já para a mãe se não pode sair da barriga dela, se não pode entrar para sair. Ele tem umas questões: 'Eu não posso entrar para sair de novo'? Da barriga né! Porque ele quer. Mas, a gente sempre fala que não: 'Não saiu'. Por mais que ele queira que a gente... Sempre pergunta para ver se a história muda né, mas a história sempre continua a mesma. (Pai 8)

A [filha adotada aos três anos] começou a perguntar bastante da história dela. Foi curioso porque logo no início ela dizia que tinha nascido da minha barriga. ... $\mathrm{E}$ eu me lembro muito, de uma psicóloga na época, nesse processo, que me perguntou "como você vai contar pra ela que ela é adotada"? E eu virei e falei: 'a garota tem três anos, ela sabe, não vou precisar contar'. Mentira! Preciso contar toda hora. Volta e meia preciso contar. ... Se a gente tivesse confirmado a história que ela estava inventando, talvez ela tivesse embarcado e refeito a própria história. Então a gente precisou constantemente dizer que não, que a gente sempre quis ela, mas que ela tinha nascido na barriga de uma outra moça, que a gente não conhece. (Mãe 3)

Cada criança apresenta uma contribuição ativa para a integração da família. Por meio da manifestação de suas inquietações e desejos, estimula a família a fazer esforços de simbolização dos processos de filiação e 
parentalidade. A simbolização permite o trabalho de apropriação subjetiva das experiências psíquicas, inscrevendo-se, fundamentalmente, em uma dimensão relacional de encontro.

Para que se inicie esse processo, questões latentes se manifestam: Qual é o significado desse pedido de nascer da barriga da mãe adotiva? É um pedido defensivo de apaziguamento das angústias referentes às origens? Ou poderíamos pensar na hipótese de uma tentativa de elaboração da história? Observamos que uma das respostas parentais de corresponder às demandas sobre as origens dos filhos foi pela via lúdica, desde a criação de jogos de nascimento da barriga adotiva até de livros sobre a história de origem.

A [filha adotiva de 3 anos] ainda está um pouco nessa fase: "Eu tava na sua barriga?". Para ela, eu já digo claramente que não estava. Para ele, eu sempre disse que não estava, mas eu sempre dizia: Ah, então brinca de vir pra minha barriga! Já com ela eu não faço mais isso, já tem um outro tempo de aprendizado. Mas que era essa coisa de eu achar nessa fase e de alguma forma passar isso pro [filho mais velho adotivo]. Quer dizer passar não, porque isso não se passa, mas de acreditar que podíamos jogar esse jogo de você não veio da minha barriga, mas vamos presumir isso. Fique aqui grudado em mim, fique em cima de mim, como se isso fosse uma maternidade biológica postiça. (Mãe 1)

De acordo com a reflexão da Mãe 1, a criação do jogo "nascer da barriga" foi inicialmente uma manifestação defensiva para lidar com a angústia da ausência dessa experiência. Ela nos apresenta um uso do brincar a serviço das defesas, como uma forma de aplacamento da ansiedade em relação à dupla filiação. Porém, podemos pensar que mesmo em uma atitude defensiva há um desejo inconsciente de buscar a simbolização, a transformação. Seguindo esse caminho, percebemos que há uma demanda por parte da criança de uma simbolização compartilhada com os pais, transformando a experiência, em estado bruto, em conteúdo simbolizável (Roussillon, 2014). A realidade do paradoxo da filiação adotiva convoca um movimento de elaboração na presença do outro.

Momentos como um dia eu conversando com os dois [os filhos adotivos] na cama. E como eu disse, o mais novo muito irreverente, muito brincalhão. Ele sempre na hora de dormir brinca, joga, e eu comecei a contar a história da adoção para os dois. Então é... e aí quando eu comecei a falar isso, o mais novo ficou quieto parou a brincadeira e ficou quieto na cama e aí falando de adoção, falando de abrigo, falando de abandono e ele quieto. Uma hora eu perguntei a ele: 'Por que você tá quieto? Por que você não continua brincando? Ou então, por que você não conversa com a gente?' Aí ele virou para mim e falou: 'É... eu não gosto de falar, eu prefiro falar de brincadeira, eu prefiro falar... eu não gosto de falar de coisa séria, né... eu prefiro brincar do que falar de coisa séria'. (Pai 8)

Como o trecho destacado ilustra, os entrevistados mencionaram a necessidade de seus filhos falarem sobre suas origens. Enriquece essa discussão a postulação de Roussillon (2019) de que "a realidade não é uma coisa em si" ( $p$. 
10), embora exista independentemente do sujeito. Ela corresponde a uma categoria psíquica construída individual e socialmente. A criação dos jogos, livros de história - produtos da "área intermediária" (Winnicott, 1975) - ilustram a manifestação de forças integradoras, que parecem ganhar vida quando há a garantia da presença de alguém.

Safra (2006) afirma que para uma pessoa experimentar suas memórias é necessário que ela esteja enraizada em um grupo, porque é no encontro com as pessoas que se possibilita o ato de narrar a biografia, favorecendo a experiência do verdadeiro self. Os participantes revelaram que foram convocados a ocuparem a função simbolizante de questões difíceis da condição humana. $O$ exercício da parentalidade envolve ser portador de uma parte da função simbolizante (Roussillon, 2019). Entendemos que quando ocorre essa convocação dos filhos aos pais para narrar as origens, por meio do brincar, coloca-se em processo o enraizamento da filiação e da parentalidade.

$O$ pedido de nascer da barriga pode ser escutado como uma tentativa de simbolizar o paradoxo da filiação com aqueles que dão novas chances de renascer. Segundo Roussillon (2019), "a saída dos paradoxos não está no próprio paradoxo, mas em seu futuro, isto é, na resposta que ele produz ou que se traz para ele, em seu modo de utilização intersubjetiva" (p.98). Pensamos na hipótese de que este pedido da criança busca um nascer na mente de seus atuais pais. Porém, nascer em alguém é possível quando há trocas intersubjetivas.

O brincar permite essa troca, gerando um modelo relacional, no qual os pais se permitem ser um dos destinos e vias de transformação dos conteúdos psíquicos dos filhos. Sendo assim, o jogo apresenta a atual organização psíquica do sujeito, possibilitando novos arranjos, abrindo espaço para um movimento processual. A internalização da noção de que a vida é um curso torna-se fundamental, pois cria no psiquismo a representação da transitoriedade inerente à subjetivação humana. Segundo Safra (2006), a criança capaz de brincar consegue abrir-se para o futuro, fundando mundos para o amanhã. Entendemos que internalizar a noção de futuro é importante para acreditar em transformações, ter esperança e resiliência.

Era uma fase, nessa época, que me doeu muito. Me custou muito, mas eu entendi que 0 [filho] estava precisando processar o sofrimento dele, o afastamento e de alguma forma a recusa da mãe biológica dele. E de alguma forma isso ia ressignificar a aproximação dele comigo. (Mãe 1)

De acordo com Ozoux-Teffaine (2018), os filhos adotados mostram que a memória de suas vidas não é estável, nem fixa, estando em transição constantemente. É possível uma evolução fantasmática de determinada realidade interna, ou seja, uma transformação simbólica do romance familiar que eles produziram em suas vidas. Poder recriar esse romance na presença dos pais 
adotivos talvez seja um caminho promissor para a organização psíquica familiar. O espaço da brincadeira em conjunto serviria, assim, como destino à necessidade de criar sentidos, projetando novos horizontes do romance familiar.

\section{CONSIDERAÇÕES FINAIS}

Propusemos nesse trabalho discutir o brincar como via importante para a solidificação da parentalidade e a integração do paradoxo da filiação adotiva. Ressaltamos que a formação da família pela adoção permite uma continuidade após descontinuidades, construindo pontes - entre ausência e presença, estranho e familiar, impossível e possível, fantasia e realidade. Consideramos que essa ponte é viabilizada pelos fenômenos transicionais, tendo como meio privilegiado o brincar.

Compreendemos que no espaço transicional da brincadeira as duras realidades da adoção e o enigma das origens podem ser "vividos" sem ameaças, sem disfarces e honestamente imaginados. Rickardsson (2017) em seu livro "Nunca deixe de acreditar - das ruas de São Paulo ao norte da Suécia", no qual relata sua história antes e depois da adoção, menciona que se sentia muito amada pela mãe biológica quando esta última lhe apresentava a dura realidade da vida, de uma maneira delicadamente honesta: "Acho que essa sua maneira de me dizer a verdade fez com que eu me sentisse amada. Ela me via e levava a sério, tanto os meus pensamentos quanto minhas dúvidas" (p. 20). Este depoimento nos faz refletir sobre o quanto, poder experimentar a verdade interna e externa, junto com o outro, possibilita a crença no amor.

Pensamos que este estudo é importante para não restringirmos a reflexão sobre os laços adotivos apenas aos hiatos presentes nessa formação familiar. Existem muitos lutos a serem elaborados, mas também um anseio por uma efetiva criação de vínculo parento-filial, expresso de diferentes formas. Desse modo, nem tudo se refere a traumas e privações do passado. Devemos estar atentos às demandas do presente, às necessidades que surgem para a sedimentação da filiação em suas mais diversas dimensões.

Postulamos, sobretudo, que o espaço dado ao brincar nas relações familiares pode auxiliar na elaboração dos fatos vividos e sentidos. A possibilidade de compartilhar as experiências emocionais nessa área intermediária (entre o interno e o externo), em alguma medida, ajuda a sedimentar a identidade familiar adotiva e a integrar o paradoxo da filiação adotiva, o qual não é para ser resolvido, mas conduzido criativamente.

Consideramos que o trabalho ilustrou, por meio das narrativas dos entrevistados, o quanto a potência da adoção está no processo da criação de uma área compartilhada e não em atos que visam a tamponar os hiatos. Desse modo, não restringimos a reflexão sobre os laços adotivos apenas às ausências presentes nessa formação familiar. Nos jogos e nas brincadeiras, pais e filhos 
entram em contato com conteúdos internos e externos de cada um, compartilhando-os, permitindo tocar o outro e serem tocados com o que há de mais íntimo e espontâneo em cada membro. Assim, nesse jogo se criam sentidos aos grandes questionamentos familiares, podendo-se ampliar o senso de esperança e tolerância à dura realidade de sermos constituídos muito mais por enigmas do que por certezas.

\section{DECLARAÇÃO DE CONFLITOS DE INTERESSE}

Não há conflitos de interesse.

\section{REFERÊNCIAS}

Abrão, M. S. (2011). Construindo vínculo entre pais e filhos adotivos. São Paulo: Primavera editorial, 2011.

Bardin, L. (2011). Análise de Conteúdo. São Paulo: Edições 70.

Ciccone, A., Gauthier, Y., Golse, B., \& Stern, D. (2016). Naissance et dévelopment de la vie psychique. Paris: Érès.

Davis, M., \& Wallbridge, D. (1982). Limite e espaço: uma introdução à obra de D. W. Winnicott. Rio de Janeiro: Imago.

Freud, S. (2006). Os três ensaios sobre a teoria da sexualidade. In Obras Psicológicas Completas de Sigmund Freud (Vol. 7). Rio de Janeiro, RJ: Imago. (Obra original publicada em 1905).

Fulgencio, L. (2016). Por que Winnicott. São Paulo: Zagadoni.

Gurfinkel, D. (2017). Relações de objeto. São Paulo: Blucher.

Herlem, F. C. (2013). Adoption: la filiation du coeur. Paris: Cavalier Bleu.

Kernberg, P. F. (1985). Child Analysis with a severely disturbed adopted child. International Journal of psychoanalytic psychotherapy, 11, 277-299.

Konicheckis, A. (2001). Paradoxes et fonctions narcissiques de la filiation. Cliniques méditerranéennes, 1(63), 143-156.

Ladvocat, C. (2018). As falhas da adoção no casal parental. In G. K. Levinzon, \& A. D. Lisondo (Org.). Adoção: desafios da contemporaneidade (pp. 99-115). São Paulo: Blucher.

Lebovici, S., \& Diatkine, R. (1988). Significado e função do brinquedo na criança. 3 ed. Porto Alegre: Artes Médicas.

Levinzon, G. K. (2009). Adoção: clínica psicanalítica. São Paulo: Casa do Psicólogo.

Levinzon, G. K. (2000). A criança adotiva na psicoterapia psicanalítica. São Paulo: Editora Escuta.

Paes, F. F., \& Zornig, S. M. A-J (2018). O brincar negativo na teoria de André Green. Cadernos de Psicanálise (CPRJ), 40(39), 147-163. 
Peiter, C. (2011). Adoção: vínculos e rupturas: do abrigo à família adotiva. São Paulo, SP: Zagodoni.

Pierron, J-P. (2003). On ne choisit pas parentes - comment pensar l'adoption et la filiation? Paris: Seuil.

Puget, J. (2015). Subjetivación discontinua y psicoanálisis. Buenos Aires: Lugar Editorial.

Queiroz, E. F. (2017). A questão do incesto na filiação por adoção. In E. F. de Queiroz \& E. M. da Silva (Orgs.). Adoção, filiação e práxis (pp. 99-119). Curitiba: CRV.

Machado, R. N., Féres-Carneiro, T., Magalhães, A., \& Mello, R. (2019). O mito de origem em famílias adotivas. Psicologia USP, 30, e160102. Epub 21 de março de 2019. https://dx.doi.org/10.1590/0103-6564e160102

Motta, I. F. (2018). Toda criança necessita ser adotada. In G. K. Levinzon \& A. D. Lisondo (Orgs.). Adoção - Desafios da contemporaneidade (pp. 235-247). São Paulo: Blucher.

Ozoux-Teffaine, O. (2018). Memórias da adoção. In G. K. Levinzon \& A. D. Lisondo (Orgs.). Adoção - Desafios da contemporaneidade (pp. 235-247). São Paulo: Blucher.

Rochel, H-L. H. I. (2018). Espaço potencial e trabalho psíquico do analista. In A. L. M. L. Silva, A. S. Magalhães, R. R. Jerez, C. S. Cerezer, N. T. S. Gonçalves, \& W. M. C. F. Cidade (Orgs.). Winnicott - Integração e Diversidade (pp. 181-191). Rio de Janeiro: Prospectiva.

Rotenberg, E. (2011). Adopción: Construyendo nuestra família. Buenos Aires: Lugar Editorial.

Rickardsson, C. (2017). Nunca deixe de acreditar - das ruas de São Paulo ao norte da Suécia. Ribeirão Preto: Novas Ideias.

Roudinesco, E. (2003). A família em desordem. Rio de Janeiro: Zahar.

Roussillon, R. (2014). Pertinence du concept de symbolisation primaire. In A. Brun \& R. Roussillon. (Org.). Formes primaires de symbolisation (pp. 155174). Paris: Dunod.

Roussillon, R. (2019). Manual da prática clínica em psicologia e psicopatologia. São Paulo: Blucher.

Safra, G. (2006). Desvelando a memória do humano - O brincar, o narrar, o corpo, o sagrado, o silêncio. São Paulo: Edições Sobornost.

Santos, A. T., \& Lajonquière, L. (2010). A sexualidade infantil e o desejo de saber: a origem da atividade intelectual nas crianças (Iniciação Científica). Faculdade de Educação USP, 6. São Paulo, SP: FEUSP. Recuperado de http:// bit.ly/2BvY7os.

Silva, C. L. R. (2011). Filhos da esperança: os caminhos da adoção e da família e seus aspectos psicológicos. Rio de Janeiro, RJ: Agbook.

Souza, H. P. de, \& Casanova, R. P. de S. (2011). Adoção: o amor faz o mundo girar mais rápido. Curitiba, PR: Juruá. 
Winnicott (1975). O Brincar e a Realidade. Rio de Janeiro: Imago.

Sobre os autores

Rebeca Nonato Machado é professora assistente da Pontifícia Universidade Católica do Rio de Janeiro, mestre e doutora em Psicológica Clínica pela Pontifícia Universidade Católica do Rio de Janeiro. Trabalha na linha "Família, Casal e criança: teoria e clínica" do programa de Pós-graduação em Psicologia Clínica da PUC-Rio, e recebe financiamento de pesquisa da FAPERJ E CNPQ para bolsas de Iniciação Científica. rebecamachado@puc-rio.br

Renata Mello é pós-doutoranda em Psicologia Clínica pela Pontifícia Universidade Católica do Rio de Janeiro, mestre e doutora em Teoria Psicanalítica pela Universidade Federal do Rio de Janeiro. Trabalha na linha "Família, Casal e criança: teoria e clínica" do programa de Pós-graduação em Psicologia Clínica da PUC-Rio, e recebe financiamento de pesquisa da CAPES. renatamello@gmail.com Terezinha Féres-Carneiro é professora titular do Departamento de Psicologia da Pontifícia Universidade Católica do Rio de Janeiro, mestre em Psicologia Clínica pela PUC-Rio, doutora em Psicologia Clínica pela PUC/SP, com Pós-doutorado em Psicoterapia de Família e Casal pela Universidade Paris-Descartes, trabalha na linha de pesquisa "Família, casal e criança: teoria e clínica" do programa de Pósgraduação em Psicologia Clínica da PUC-Rio, e recebe financiamento do CNPq e da FAPERJ. teferca@puc-rio.br

Certificamos que todos os autores participaram suficientemente do trabalho para tornar pública sua responsabilidade pelo conteúdo. A contribuição de cada autor pode ser atribuída como se segue: Rebeca N. Machado contribuiu para a conceitualização, investigação e visualização do artigo; Rebeca N. Machado e Renata Mello fizeram a redação do artigo e Rebeca N. Machado, Renata Mello e Terezinha Féres-Carneiro são responsáveis pela redação final (revisão e edição).

Os autores agradecem à FAPERJ e ao CNPq pelo financiamento. Agradecem, ademais, ao grupo de pesquisa composto pelas bolsistas Letícia da Cunha Soares (IC/PIBIC), Maria Antônia Pereira Monteiro (IC/FAPERJ), Anna Carolina Dias Mallet Soares (IC/PUC-Rio), Júlia Tavares Rodrigues Barros Lima (IC/PUC-Rio), Laura Souza Eletherio de Oliveira (IC/PUC-Rio), Vanessa Bensa de Oliveira Neves (AT/PUC-Rio). Mestranda Cláudia Regina da Costa Pinna (VRC/PUC-Rio) pelo apoio na coleta e análise de dados, bem como na discussão dos resultados com a literatura.

Recebido em: 07/05/2019

Revisado em: 02/08/2019

Aceito em: 15/12/2019 